\title{
Mission engineering for the RETALT VTVL launcher
}

\author{
Gabriele De Zaiacomo ${ }^{1} \cdot$ Gonzalo Blanco Arnao $^{1} \cdot$ Riccardo Bunt $^{1} \cdot$ Davide Bonetti $^{1}$
}

Received: 8 July 2021 / Revised: 13 December 2021 / Accepted: 15 December 2021 / Published online: 4 February 2022

(c) The Author(s) 2022

\begin{abstract}
In the last decade, the rapid and successful development of reusable launch systems such as SpaceX' Falcon 9 demonstrated both the operational feasibility of reusable launchers and their economic viability. The objective of recovering a launcher or a launcher's booster requires to safely return the launch vehicle from orbital or sub-orbital conditions to a soft landing. To increase the reusability, decrease the turnaround time and reduce costs, a precise touchdown on a pre-defined landing site or on a floating barge on the Ocean is preferred to splashdown in the water, due mainly to the highly detrimental effect of the salted water on the launcher components and equipment. The project RETALT (Retro Propulsion Assisted Landing Technologies) was funded by the EU Horizon 2020 program to study and develop critical technologies for launcher recovery based on retro-propulsion. In this context, and based on in-house experience and tools, DEIMOS Space carried out the mission engineering of the RETALT1 vehicle concept to assess the feasibility of a return mission, from a wide range of Main Engine Cut-Off (MECO) conditions, when the stage is separated from the rest of the launch vehicle, in line with the available propellant budget, and while maintaining the peak entry conditions within acceptable limits. Either a DownRange Landing (DRL) on a drone ship at sea or a Return To Launch Site (RTLS) to land in the proximity of the launch pad is performed based on the velocity and distance at MECO from the launch site. For the landing burn, a safe splashdown approach has been implemented to avoid damaging the ground infrastructure in case of anomalies during the flight. Based on the mission feasibility assessment, the needs for the vehicle recovery have been identified, leading to the definition of preliminary mission requirements at the system and subsystem level. Consequently, the consolidation of the return mission design was possible and optimised trajectories have been defined for the DRL and RTLS scenarios.
\end{abstract}

Keywords Launcher - GNC · Optimal guidance - Successive convexification · Hybrid navigation · Optimum control · Reusability

\section{Introduction}

Launch vehicle reusability is currently the most effective way of reducing the cost of access to space, which is a key endeavour to the commercialization of space [1]. Nevertheless, the technical challenge of recovering a launcher or a launcher's stage after a launch mission is large and the economic effort to develop the necessary technology to carry out routinely successful launcher recovery missions is enormous. For these reasons, only two companies (SpaceX and Blue Origin) have developed so far the capability of

Gabriele De Zaiacomo

gabriele.dezaiacomo@deimos-space.com

1 DEIMOS Space S.L.U., Ronda de Poniente, 19, Tres Cantos, 28760 Madrid, Spain designing, manufacturing, and operating sustainable reusable launch systems.

In this context, the EU and ESA have made increasing efforts to achieve the goal of making launcher reusability the state-of-the-art in Europe. One such effort is RETALT (Retro Propulsion Assisted Landing Technologies) [2], a Horizon 2020 project with six partners in four European countries, with the goal of investigating launch system reusability technology for two classes of launch vehicles with retro-propulsive recovery (Fig. 1): RETALT1, a two-stage to orbit (TSTO) launcher, similar to SpaceX's Falcon 9, with the recovery of the first stage only; and RETALT2, a single-stage to orbit (SSTO) vehicle, similar to the DC-X, where recovery of the full vehicle is foreseen. The project aims to increase the Technology Readiness Level (TRL) of the recovery technologies up to 5 for structures and mechanisms, and up to TRL 3 for GNC. 
Fig. 1 RETALT1 and RETALT2 concepts launcher has to face during the return phase allows identifying the needs in terms of performance and the design drivers to achieve the mission objectives and enable reusability. The mission constraints will limit the space of the mission solution and will contribute to the identification of the mission requirements.

- Mission Design the flying qualities of the return vehicle are assessed with respect to the flight envelope identified to evaluate its trimmability and stability characteristics. Then, the mission and the reference trajectories are consolidated to support the development of the different technologies necessary to enable the recovery and, therefore, the reusability of the launcher.

- Mission Verification the mission performance is evaluated in presence of uncertainties to assess the robustness of the mission design in non-nominal conditions, and extract the consolidated flight and landing loads. The flight qualities defined during the mission design are also verified.

The mission engineering is the focus of the present paper. Section 2 presents the mission scenario considered for RETALT. Sections 3 presents the mission feasibility analysis, while Sects. 4 and 5 present the mission design focusing on the flight qualities aspects and the trajectory consolidation, respectively. Finally, Sect. 6 presents the main conclusions and the way forward.

\section{Mission scenario}

The baseline configuration and the main focus of the project and this paper is RETALT1. The vehicle operates similarly to a typical launcher until separation, after which two scenarios for the first stage recovery are considered: Downrange Landing (DRL) and Return to Launch Site (RTLS), illustrated in Fig. 2. The former foresees a landing at sea on a floating barge while the latter differs in the use of a postseparation flip manoeuvre and boostback burn that modifies the ballistic arc to allow a landing at or near the launch site.

Both scenarios employ a re-entry burn, to reduce velocity and dispersions, and an active aerodynamic descent phase enabled by the use of control surfaces. Finally, the first stage recovery mission ends with an engine-powered descent, which slows the vehicle down to a pinpoint and soft vertical landing. Different Aerodynamic Control Surface (ACS) configurations are considered for the RETALT1 concept, including interstage petals (IS), planar fins (PF), and grid fins (GF) (see Fig. 3). Aerodynamic databases have been produced in RETALT for all the configurations $[5,6]$.

The capability of recovering the launcher's first stage from a wide range of launch mission scenarios is key in enabling a broad combination of payloads and injection orbits, 


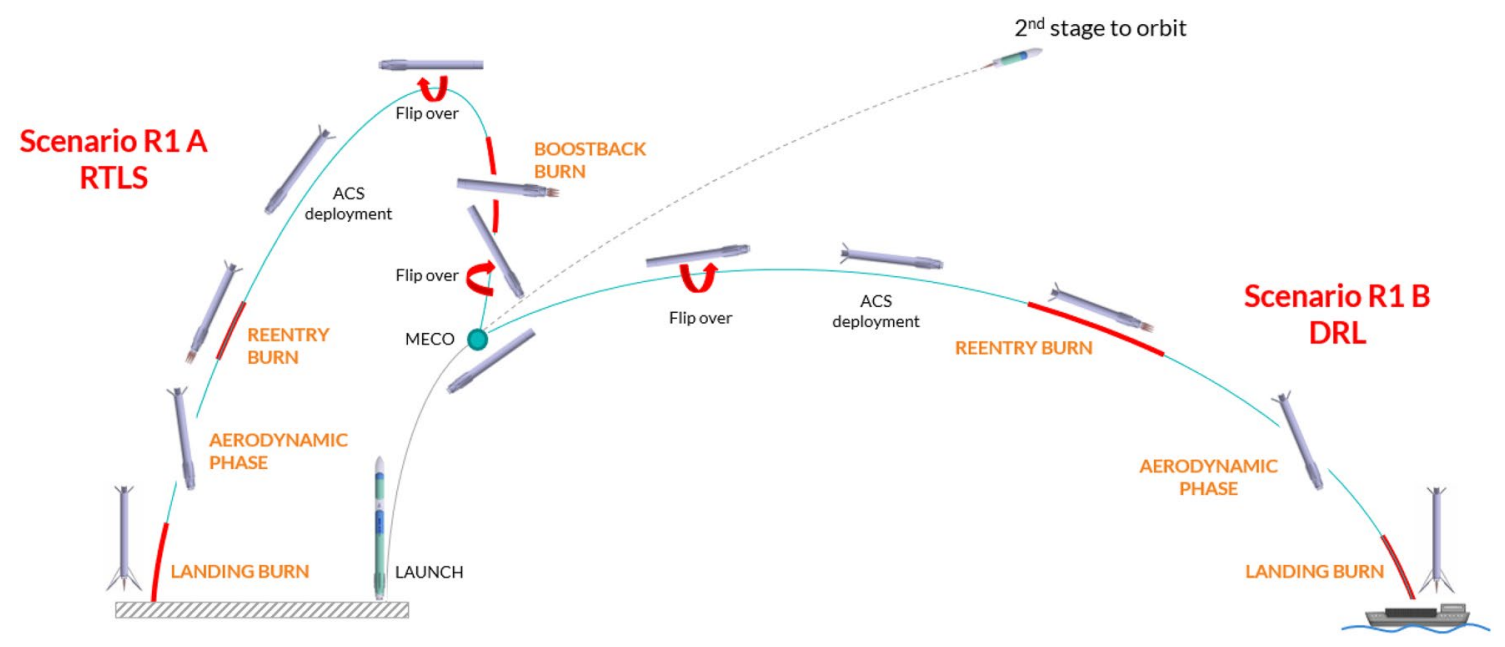

Fig. 2 RETALT1 return mission concept
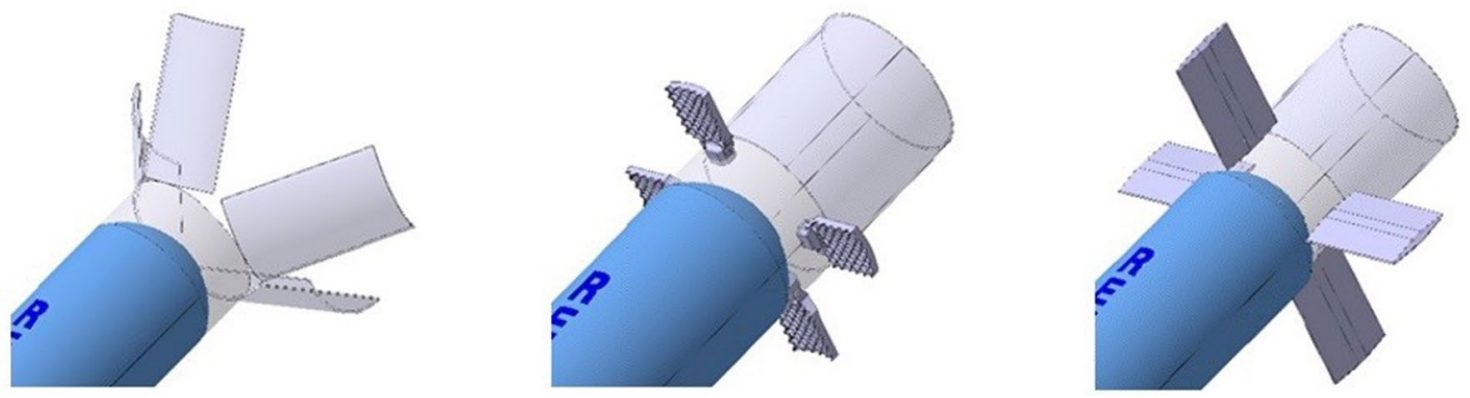

Fig. 3 RETALT1 ACS configurations: interstage petals (left), grid fins (center), and planar fins (right)

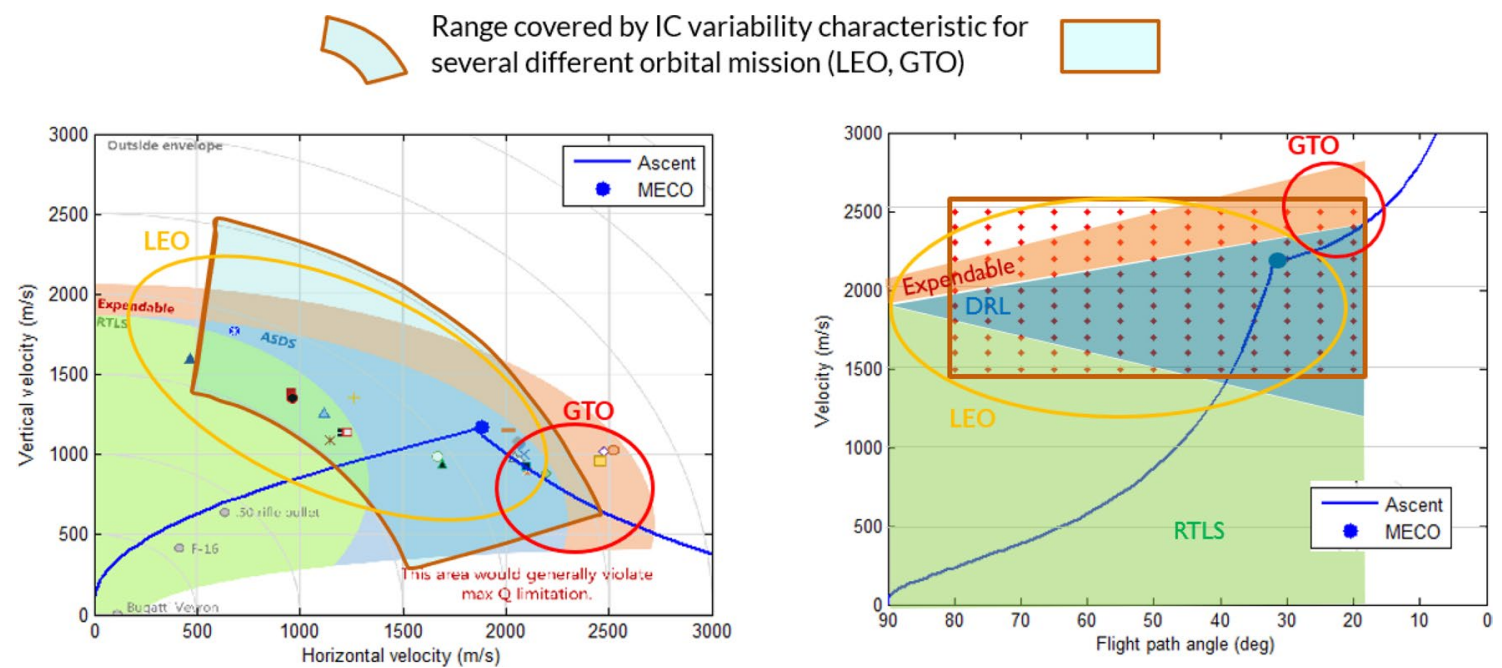

Fig. 4 Initial conditions variability for RETALT 1 mission analysis (conditions at MECO for reference Falcon 9 missions are also reported [7]) 
providing the launcher with the flexibility to meet the needs of different customers. Figure 4 shows, on the left side, the expected conditions at MECO for the SpaceX Falcon 9 [7] in terms of horizontal and vertical velocity (or, equivalently, velocity and flight path angle on the right side), and reports the conditions for specific missions.

For a given range of conditions at MECO, a specific recovery strategy is allowed (RTLS: return to launch site, ASDS/DRL: autonomous spaceport drone ship/downrange landing). Characteristic conditions for LEO and GTO missions could thus be mapped on the expected variability, and a representative variability in terms of velocity and FPA at MECO could be identified to cover the mission scenarios envisaged for RETALT1 (the light blue area in Fig. 4, which on the right side also reports the grid of initial conditions used for the analysis). In this way, the results obtained are representative of the expected range of applicability of RETALT1. A preliminary concept trajectory was identified for RETALT1 [2], and is also shown in the figure (blue line). The concept configuration of the RETALT1 first stage was designed assuming the use of Vulcain-like engines [2], and has a dry mass of 59.3 tons and 57 tons of propellant available for the return maneuvers (50 tons plus 7 reserve).

\section{Mission feasibility analysis}

The mission feasibility analysis focuses on the assessment of the capabilities of the proposed configurations to perform a return mission. The exploration of the flight envelope identifies the conditions that the launcher has to face during the return. The assessment is carried out by identifying the needs in terms of performance and the design drivers to achieve the mission objectives and to enable recovery and thus reusability. The analysis of the recovery capability allowed the preliminary definition of the flight and landing loads that contribute to the sizing of the aerodynamic actuators [8]. A bottom-up approach was implemented, starting the analysis from the landing phase, then addressing the aerodynamic phase, and finally the propulsive phases (reentry and boostback burns). The analysis of the landing and aerodynamic phases is common for all scenarios for each vehicle, while the analysis of the re-entry and boostback burns depends on the mission scenarios considered.

\subsection{Landing phase}

The primary objective of the landing phase is to successfully land the vehicle reaching zero velocity at touchdown, and targeting a precise landing site compensating the residual trajectory dispersions and achieving pinpoint landing. In addition, to avoid an uncontrolled impact on the landing pad in case of off-nominal functioning of one of the recovery systems, a safe landing approach is proposed, targeting the reference ballistic trajectory at a certain distance from the landing site, such that the vehicle will safely splashdown or impact on a non-dangerous zone in case of off-nominal situations or failures. A dedicated maneuver during landing will correctly target the landing site in case everything is nominal (Fig. 5).

The capability of providing lateral maneuvering is, therefore, necessary, and it is obtained by changing the attitude of the thrust vector during the landing phase. A g-turn approach lacks the capability to provide lateral control, and a guidance law was defined to bring the booster to touchdown. The aerodynamic drag was not considered in the current analysis, being this condition a worst case for the propellant consumption during the landing phase. The different launcher configurations mainly affect the variability in the trajectory conditions at the end of the aerodynamic phase, and the capability to carry out a successful landing, as well as the propellant required to do so, depends on the trajectory conditions (Fig. 6).

Figure 6 shows on one side that if the landing burn starts too late, there is not enough time to land with zero velocity (black region on the lower side of the plots). On the other, if it starts too early the propellant required to land increases and landing is not possible if the available propellant is less than the required one (black region on the upper side of the plots). For the configuration with the interstage petals, that maximizes the braking capability during the aerodynamic phase allowing to decelerate down to Mach 0.3-0.6, depending on the altitude at which the landing burn is started, about 9 tons of propellant would assure landing success for pitch

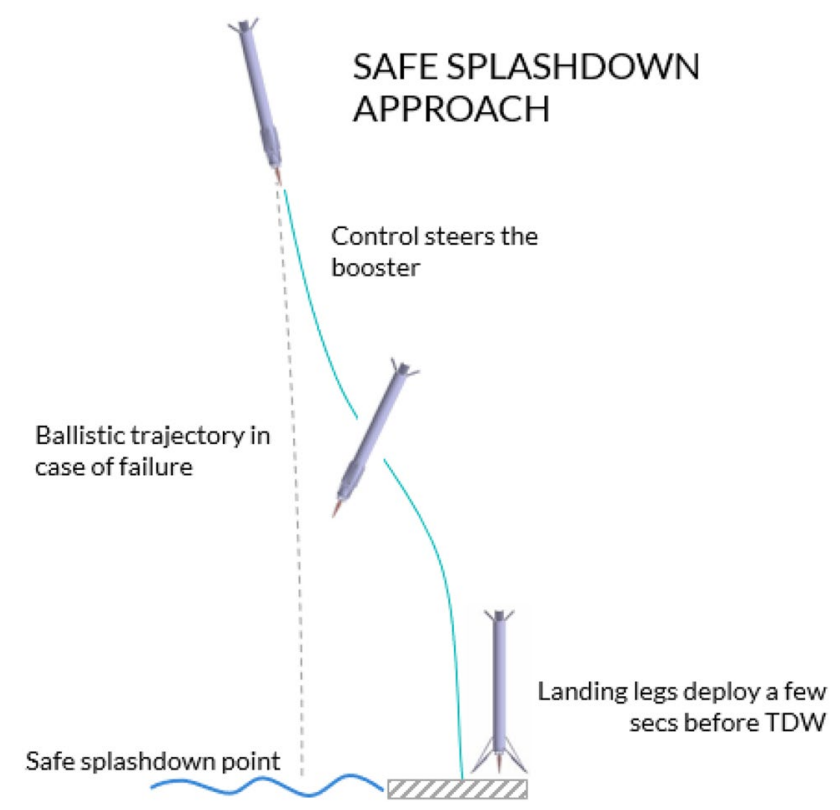

Fig. 5 Safe splashdown approach 


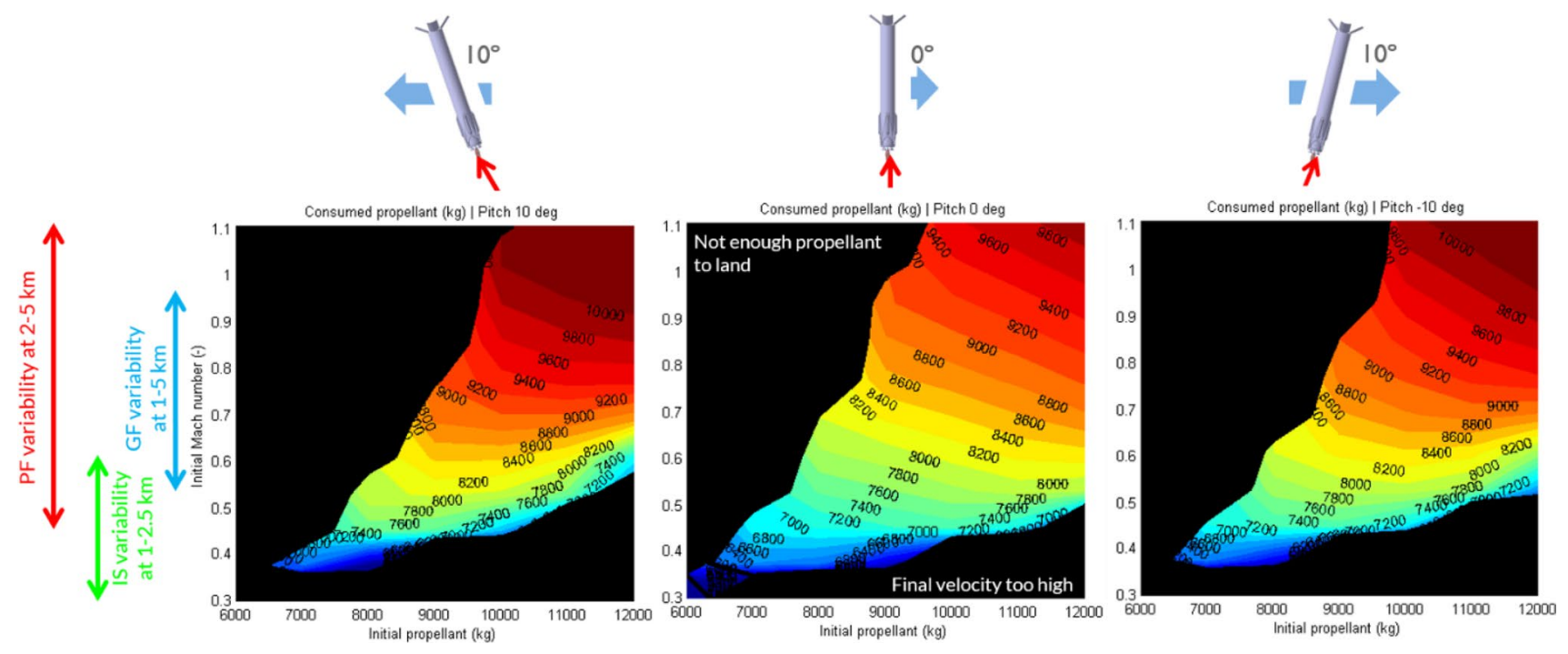

Fig. 6 Propellant consumption, RETALT1 landing phase

angles up to $10 \mathrm{deg}$. Delta pitch angles above $10 \mathrm{deg}$ significantly reduce the landing success region. With this pitch authority, the range capability during the landing phase is about $300 \mathrm{~m}$. The alternative planar fins and grid fins configurations, with a lower braking capability, require about 2 tons of additional propellant, bringing the total propellant consumption for the landing phase up to 11 tons. It is not recommended to allocate to the landing phase more propellant: it is not necessary to perform the landing and it will negatively affect the payload capability. The range capability increases up to about $500 \mathrm{~m}$ thanks to the earlier activation of the landing burn.

\subsection{Aerodynamic phase}

The objective of the aerodynamic entry phase is to successfully slow the vehicle down to the desired initial conditions for the landing phase while maintaining the thermomechanical loads within the required limits. In addition, it has to contribute to the trajectory control, compensating the residual trajectory dispersions after the re-entry burn and the trajectory dispersions that could be accumulated during the aerodynamic flight due to uncertainties.

During the aerodynamic entry phase, the aerodynamic drag slows the vehicle from hypersonic velocity down to supersonic and eventually subsonic velocity, depending on the conditions at which the landing burn is initiated. The aero-thermo-mechanical loads are important and should be limited to the maximum values that the vehicle structure and TPS can withstand. The orientation of the vehicle with respect to the velocity vector during the aerodynamic phase, i.e. the aerodynamic trim angle, determines the aerodynamic performance of the vehicle. In the case of a ballistic flight, the trim angle of attack is $180 \mathrm{deg}$, lift is zero, and the capability to control the position is neglected. Deployable surfaces could increase the drag coefficient without changing the AoA, having an impact on the peak loads experienced during the flight. When the trim AoA is different than $180 \mathrm{deg}$, the aerodynamic efficiency is non-zero, and some range capability exists. Lift and drag depend on the vehicle attitude, and deployable surfaces are needed to trim the vehicle. These surfaces can also contribute to further increasing the drag coefficient. The aero-thermo-mechanical loads during the aerodynamic phase depends on the drag characteristics of the vehicle and on the velocity conditions at the beginning of the aerodynamic phase (see Fig. 7, where the drag coefficient range covers the expected variability from a clean vehicle configuration to the configuration with the interstage petals unfolded; the grid fins and planar fins configurations show performances that are in between [6]). In particular, the maximum axial g-load and heat flux experienced during the aerodynamic phase depend mainly on the initial conditions, with a load factor always below $8 \mathrm{~g}$. The peak dynamic pressure depends primarily on the drag coefficient, and secondly on the initial conditions. From the point of view of the aerobraking needs, the results of this analysis show that unfolding the interstage will decrease the peak dynamic pressure during the flight, and in general decrease the loads. Anyhow, it is possible to maintain the dynamic pressure under the limit even with the clean configuration by either decreasing the initial velocity - that is, performing a re-entry burn and slowing the vehicle to the desired velocity - or by increasing the drag coefficient flying the vehicle with a trim angle different than $180 \mathrm{deg}$. Clearly, a stronger re-entry burn would imply a higher propellant consumption. 
Fig. 7 Expected peak loads during the aerodynamic entry, RETALT1 aerodynamic phase

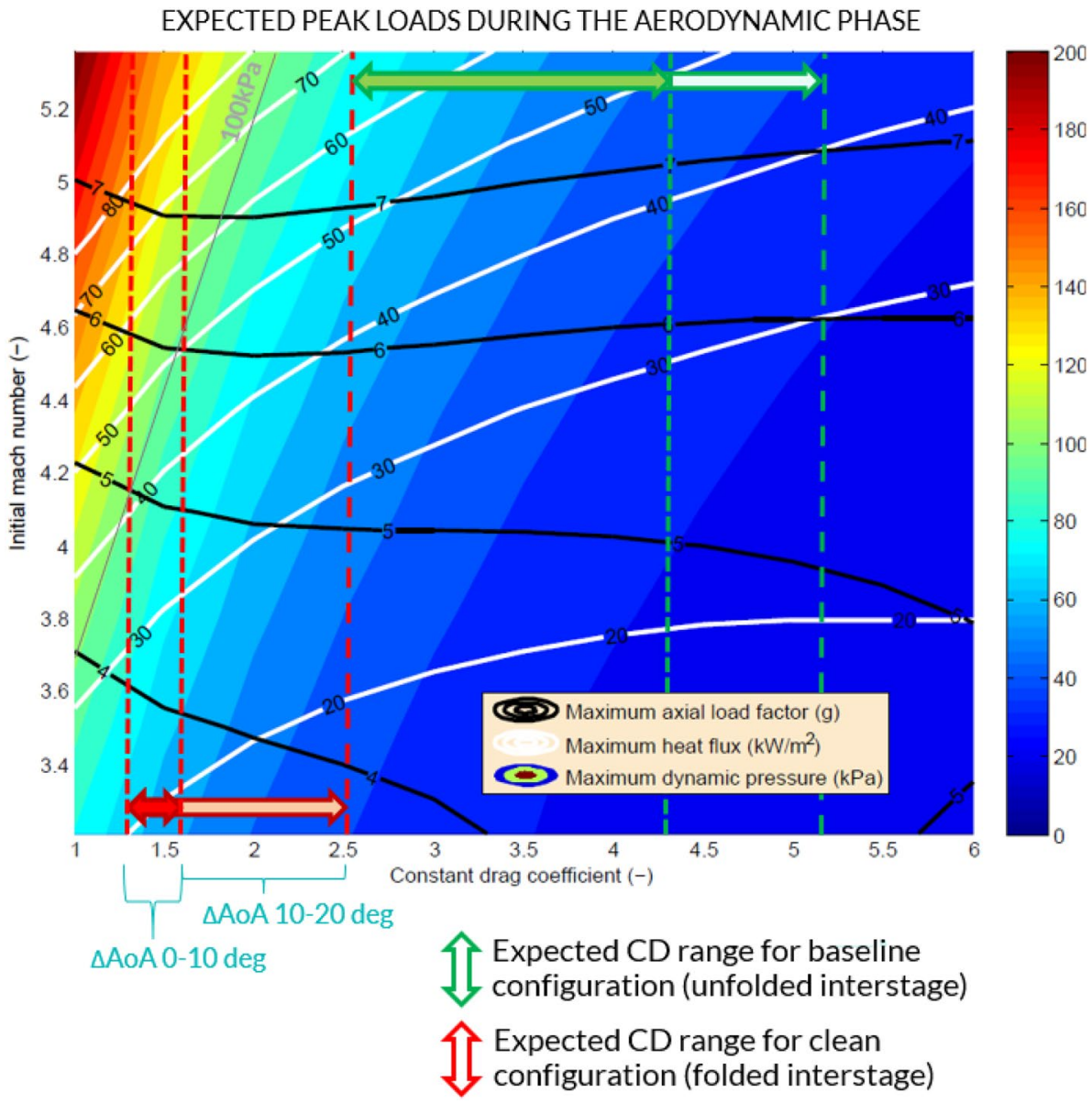

The dispersions accumulated during the aerodynamic phase need to be compensated by trajectory maneuvering during the same phase, to allow the pinpoint landing. The vehicle configuration shall, therefore, provide enough trajectory control capability to perform such a compensation. Therefore, trim flight is considered the baseline strategy for the aerodynamic entry: it will enable longitudinal and lateral trajectory control, and will also contribute to limiting the aero-thermo-mechanical loads during flight. An analysis of the trim flight characteristics was carried out for the different configurations, considering variable initial conditions and AoA during the aerodynamic flight. The peak aero-thermomechanical loads have been computed as well as the associated range capability. Figure 8 maps the range capability for the planar fins configuration with respect to the trim AoA and the initial Mach. The contour lines of the aerothermo-mechanical loads are also shown. For RETALT1, a maximum dynamic pressure of $100 \mathrm{kPa}$ and lateral g-loads of $2.5 \mathrm{~g}$ were assumed as constraints, limiting the space of the solution for the aerodynamic phase to the bright area in Fig. 8. A comparison between the three configurations shows how the use of the interstage petals allows to start the aerodynamic phase at a higher Mach number, and, therefore, requires a shorter re-entry burn, minimizing the propellant needed for the re-entry burn, while the use of planar fins maximizes the range capability during the aerodynamic phase (Table 1). The use of the interstage petals would allow saving about 7 tons of propellant with respect to the case in which the grid fins are used, and about 9 tons with respect to the planar fins. Flying the aerodynamic phase with trim angles up to $\triangle \mathrm{AoA}$ of $10 \mathrm{deg}$ would be compatible with the constraints. It is clear, however, that the L/D during the aerodynamic phase needs to be maximized to provide enough margin for the trajectory control, compatible with the maximum loads. Additional options to increase the range capability include either a further reduction of the expected loads by designing a more aggressive burn, or an increase of the maximum lateral g-load that the structure could withstand. For example, an increase to $3 \mathrm{~g}$ in the lateral g-load leads to an increase of about $50 \%$ in the range capability, according to the results obtained. The results presented here were used by the partners of the RETALT project for the sizing of the aerodynamic control surfaces [8]. 


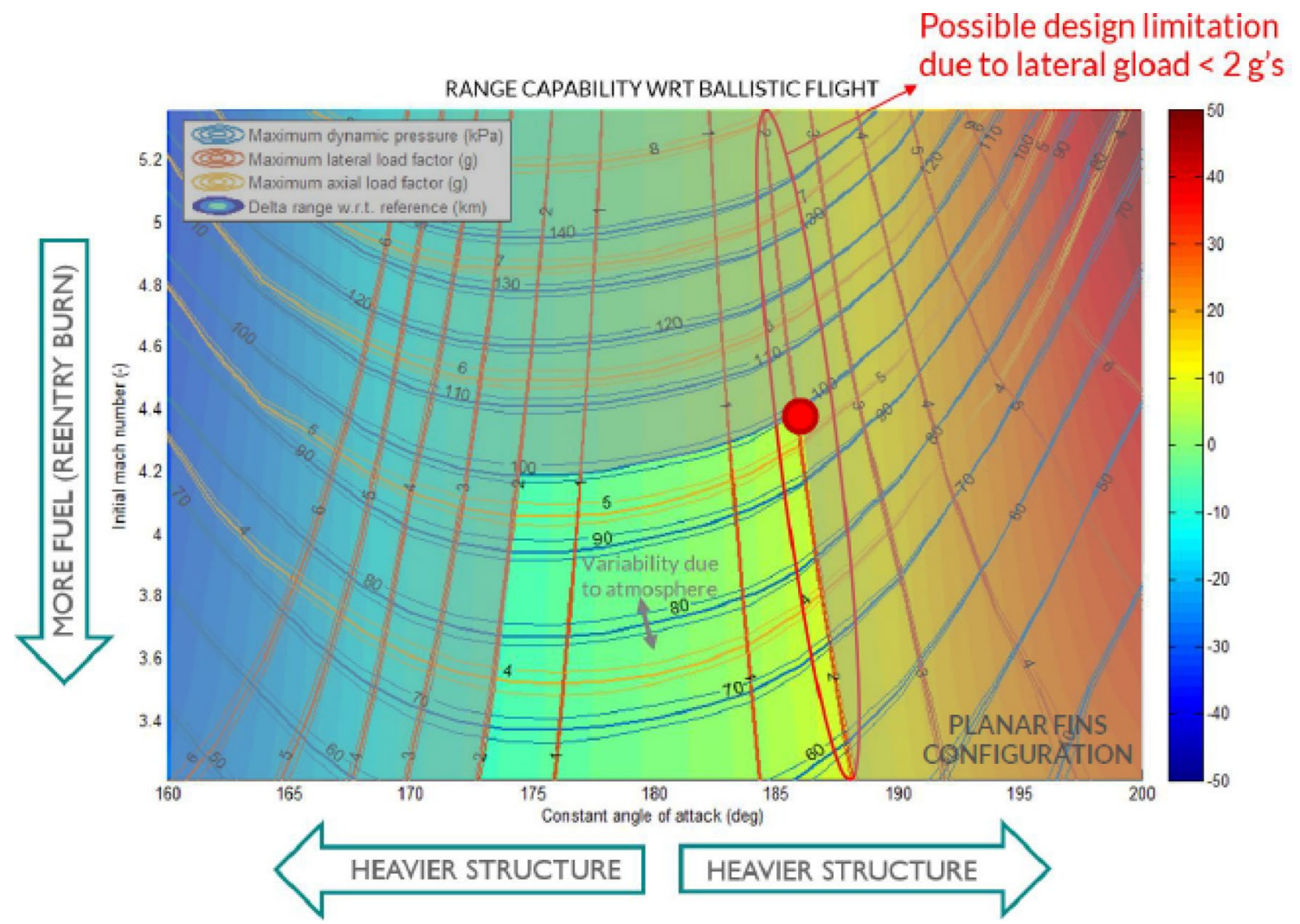

Fig. 8 Flight capability analysis for a trim flight with the PF configuration, RETALT1 aerodynamic phase

Table 1 Comparison of the trim flight characteristics, RETALT1 aerodynamic phase

\begin{tabular}{lllllrl}
\hline Configuration & \multicolumn{2}{l}{ Upper limit for the start of the aerodynamic phase } & & \multicolumn{2}{c}{$\begin{array}{l}\text { Mach } 3.2 \text { (lower limit for the start of } \\
\text { the aerodynamic phase) }\end{array}$} \\
\cline { 2 - 3 } & Mach number & Maximum $\Delta$ AoA & Range capability & & Maximum $\Delta$ AoA & Range capability \\
\hline Petals & Mach 5.2 & $\pm 6 \mathrm{deg}$ & $\pm 3.2 \mathrm{~km}$ & & $\pm 12 \mathrm{deg}$ & $\pm 4.4 \mathrm{~km}$ \\
Planar fins & Mach 4.4 & $\pm 6 \mathrm{deg}$ & $\pm 7.3 \mathrm{~km}$ & & $\pm 8 \mathrm{deg}$ & $\pm 9.2 \mathrm{~km}$ \\
Grid fins & Mach 4.6 & $\pm 5 \mathrm{deg}$ & $\pm 6.5 \mathrm{~km}$ & & $\pm 10 \mathrm{deg}$ & $\pm 8.7 \mathrm{~km}$ \\
Clean & Mach 4.4 & $\pm 6 \mathrm{deg}$ & $\pm 6.9 \mathrm{~km}$ & & $\pm 10 \mathrm{deg}$ & $\pm 9 \mathrm{~km}$ \\
\hline
\end{tabular}

\subsection{Re-entry burn}

The objective of the re-entry burn is to decrease the velocity of the vehicle making use of the propulsion system and thus maintain the aero-thermo-mechanical loads under control during the following aerodynamic phase. In addition, the control of the thrust vector attitude would enable trajectory control, contributing to the compensation of trajectory dispersions accumulated during the high-altitude aerodynamic flight due to uncertainties or errors with respect to the reference conditions. The performance during the re-entry burn depends on the starting point of the burn, its duration, and the initial conditions at the start of the burn. Preliminary analyses showed that the start of the re-entry burn cannot be tuned too much, and initiation of the re-entry burn at $70 \mathrm{~km}$ of altitude, as for the concept trajectories [2], is, therefore, assumed as a baseline.

In case a downrange landing (DRL) is performed, the reentry burn is the only active maneuver occurring between MECO and the aerodynamic phase, and the initial conditions of the re-entry burn only depend on the conditions at MECO.

Figure 9 shows as an example the peak dynamic pressure observed during the aerodynamic phase for the planar fins configuration, as a function of the Mach number at which the re-entry burn is ended and of the conditions at MECO, for different trim conditions. The cut-off and MECO coordinates for the concept trajectories are reported for reference. Figure 10 shows the same results for the grid fins configuration, limited to the AoA of 185 deg trim solution. As expected, if the aerodynamic phase is flown with an $A o A \neq 180 \mathrm{deg}$, 


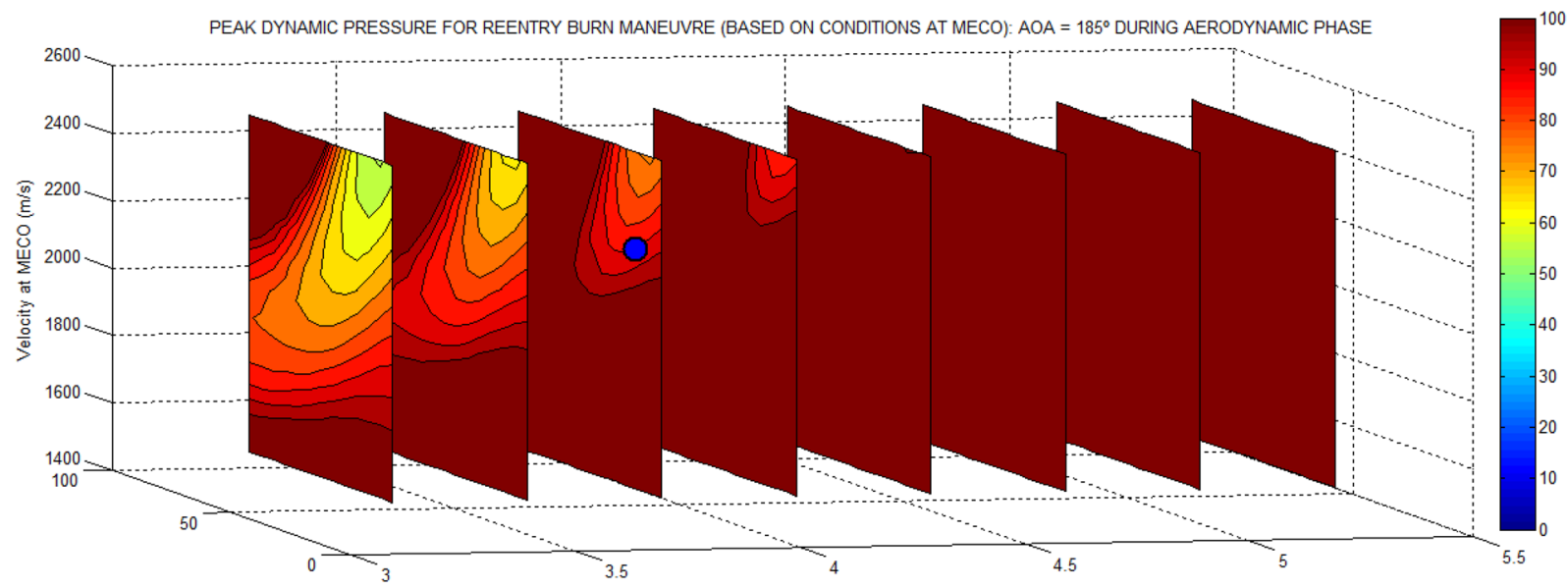

Flight path angle at MECO (deg)

Mach number at re-entry burn cut off ()

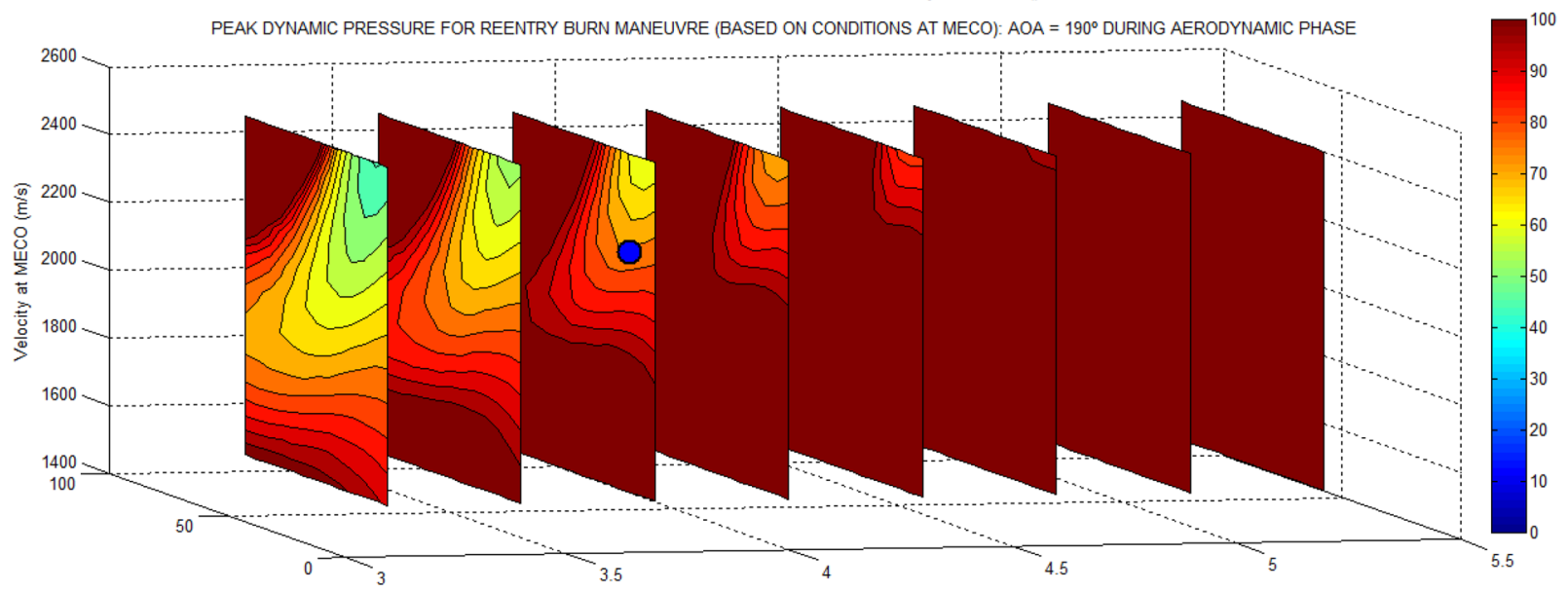

Flight path angle at MECO (deg)

Mach number at re-entry burn cut off ()

End of re-entry burn for DSC 70-4.0-5.0

Fig. 9 Expected Expected maximum dynamic pressure during aerodynamic entry after the re-entry burn for the PF configuration, RETALT1 reentry burn

the drag increases, and the feasibility region, defined by the $100 \mathrm{kPa}$ limit, improves significantly. In addition, the grid fins configuration performs slightly better than the planar fins configuration, due to the slightly higher drag produced. The propellant consumption during the re-entry burn is comparable for the different aerodynamic configurations explored due to the low influence of aerodynamics on the trajectory during this phase. The main difference between the different configurations is the feasibility domain that changes due to its dependency on the aerodynamic phase. Modifying the AoA strategy during the aerodynamic phase, the feasibility domain opens up to shorter re-entry burns, enabling the booster recovery for a wider range of conditions at MECO, and reducing the fuel consumption for a given set of conditions at MECO. The trajectory control capability depends on the duration of the burn itself, and on the relative angle between the thrust and the velocity vector. As for the aerodynamic phase, the lateral load factor is the active constraint that limits the trajectory correction capability. Depending on the burn duration, the range capability varies between 2 and $3 \mathrm{~km}$.

\subsection{Boostback burn}

In case a return to launch site is targeted, two propulsion maneuvers are considered between MECO and the aerodynamic phase: a boostback burn is required to target the correct landing site and a second (re-entry) burn could be also executed, if necessary, to slow down the vehicle and maintain the aerodynamic entry loads under control. The main objective of the boostback burn is to change the direction of the velocity and correctly target the desired landing site: the launch pad, or an alternative landing pad close to the launch pad (Fig. 11). The analysis of the recovery capability 


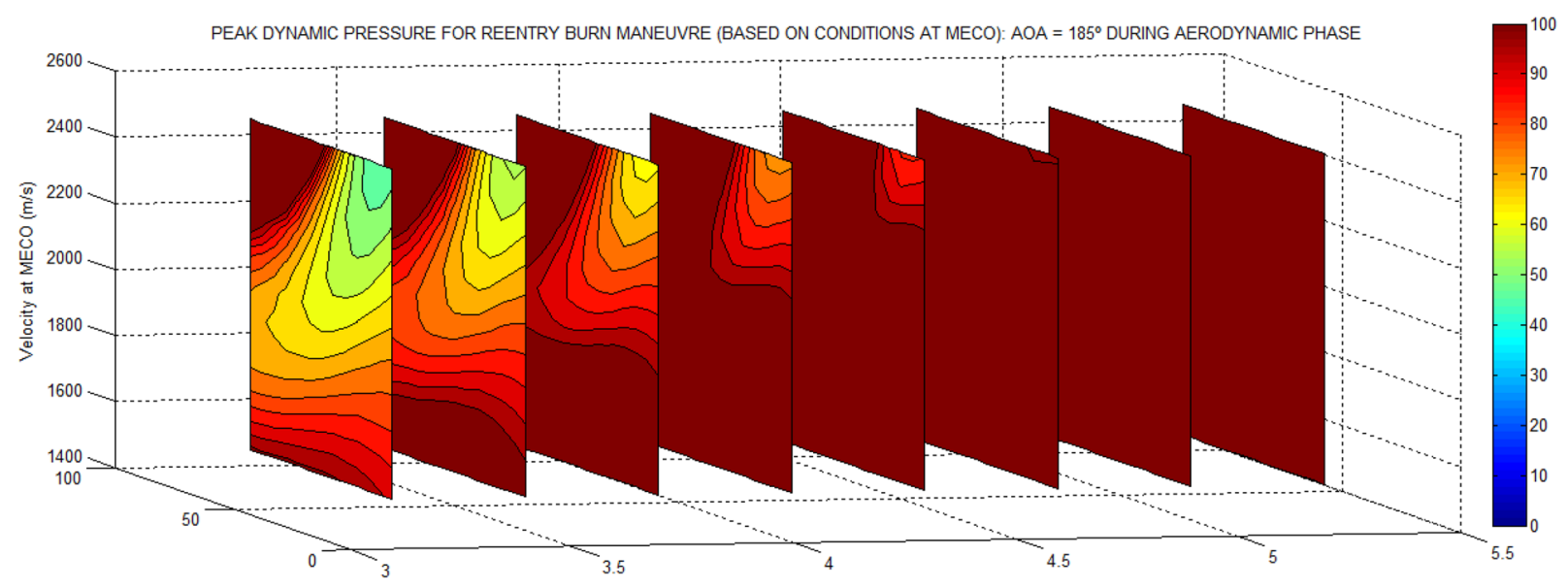

Flight path angle at MECO (deg)

Mach number at re-entry burn cut off ()

Fig. 10 Expected maximum dynamic pressure during aerodynamic entry after the re-entry burn for the GF configuration, RETALT1 re-entry burn

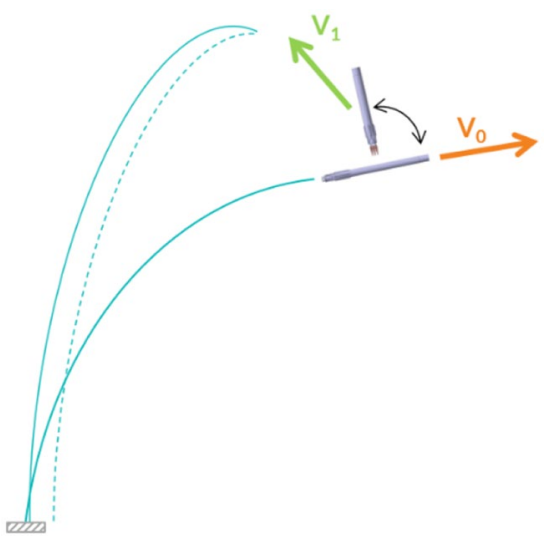

Fig. 11 Boostback manoeuvre concept for the boostback burn focuses on the identification of the propellant required to achieve the inversion of the velocity and the targeting of the landing site. As for the DRL analysis, also for the RTLS the recovery capability analysis is carried out considering the same variability in terms of conditions at MECO defined in Sect. 2. A third dimension has been added, considering also a variable distance from the launch site at MECO.

The results of the analysis show that RTLS from typical GTO missions' conditions at MECO would require too much propellant (the void regions in Fig. 12 correspond to $\geq 50$ tons of propellant, the limit considered at the system level). The feasibility region in terms of initial conditions varies almost linearly with the propellant consumption. For the

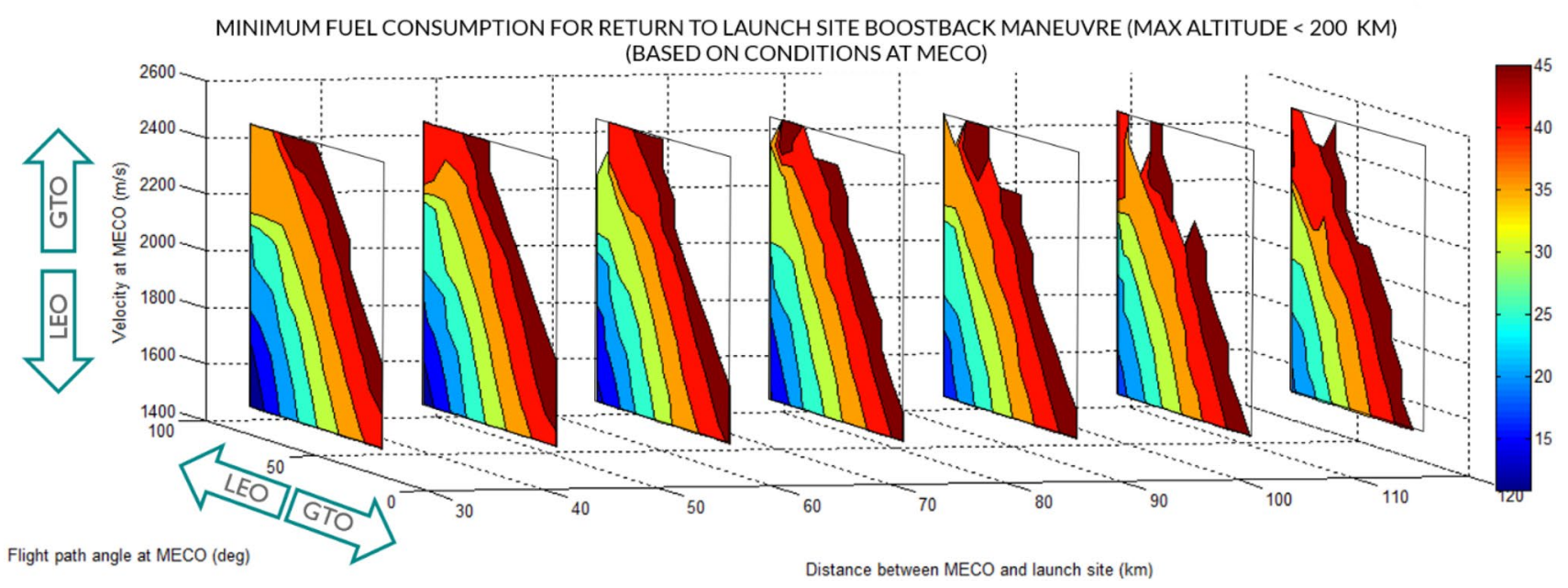

Fig. 12 Propellant consumption (tons) for the boostback burn, RETALT1 boostback phase 
sake of comparison, if the Falcon 9 declared performance is mapped based on the MECO conditions' variability (see Fig. 4), it can be observed that the region compatible with RTLS for SpaceX (identified between 1500 and $1800 \mathrm{~m} / \mathrm{s}$, and $80-45$ deg in FPA) corresponds to a fuel consumption of the boostback burn between 10 and 30 tons for RETALT1, depending on the distance from the landing site (LS) at MECO. If the propellant dedicated to the boostback burn is limited, for example, at 15 tons, it means that the RTLS option could be available for RETALT1 only if the ascent trajectory is designed such that MECO occurs at a maximum distance from the launch site below approximately $70 \mathrm{~km}$, and targeting very specific conditions in terms of velocity and FPA at MECO, with a reduced variability.

In general, the performance map obtained with this recovery capability analysis could be used to verify the compatibility of the RTLS option for a given launcher mission scenario considered. Of course, the complete propellant budget shall be taken into account, considering also the re-entry burn and the landing phase needs.

In addition, the boostback maneuver will determine the characteristics of the ballistic flight and, therefore, the need for the second (re-entry) burn to slow the vehicle and thus maintain the aero-thermo-mechanical loads under control during the following aerodynamic entry phase, as well as the initial conditions for the re-entry burn.

\subsection{Identification of the performance needs}

Based on the results of the recovery capability analysis, the performance needs are identified for the two proposed recovery strategies (DRL and RTLS) to enable the re-entry and landing of the RETALT1 first stage.

The overall propellant budget for the DRL scenario can be computed building an end-2-end performance map taking into account the propellant consumption required for the re-entry burn and for the landing burn. A constant AoA of $185 \mathrm{deg}$ is assumed during the aerodynamic phase (with the exception of the petals configuration), compatible with the maximum lateral loads for the full range of initial conditions for the aerodynamic phase for all configurations. In addition, it provides some margins with respect to the constraint to allow for active trajectory control during the flight in case of uncertainties. The mission design will consolidate the reference trajectory optimizing the AoA profile during the aerodynamic phase, but the value assumed for the definition of the overall propellant budget could be representative of the reference performance. The region of FPA/velocity at MECO for which a recovery mission is compatible with the available propellant and the structural constraints is defined as the feasible domain for the return mission. For the planar fins configuration (Fig. 13), the maximum dynamic pressure limit prevents to perform the recovery of the first stage for those launch missions that have very steep FPA and very high-speed conditions at MECO. The maximum propellant available of 50 tons limits the duration of the re-entry burn for very high speed and shallow conditions at MECO, characteristics of launch missions to GTO. Anyhow, the expected peak dynamic pressure during the aerodynamic phase is expected to remain below the limit. The use of grid fins (Fig. 14) permits saving up to about 2.2 tons on average for the same mission (any given set of conditions at MECO), that is, about $4.5 \%$ on the total propellant budget. But this

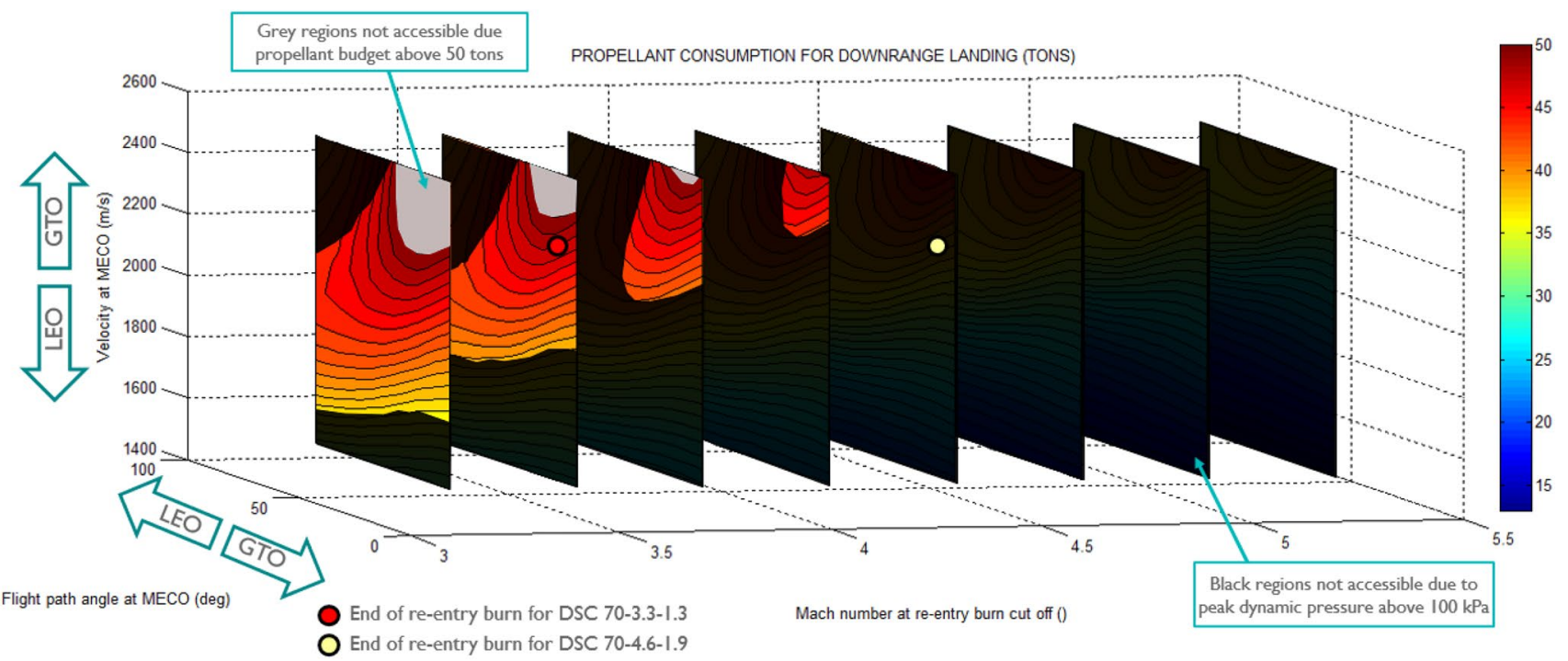

Fig. 13 End-2-end propellant budget as a function of conditions at MECO, "planar fins" configuration with AoA $=185$ deg during the aerodynamic phase, RETALT1 DRL 


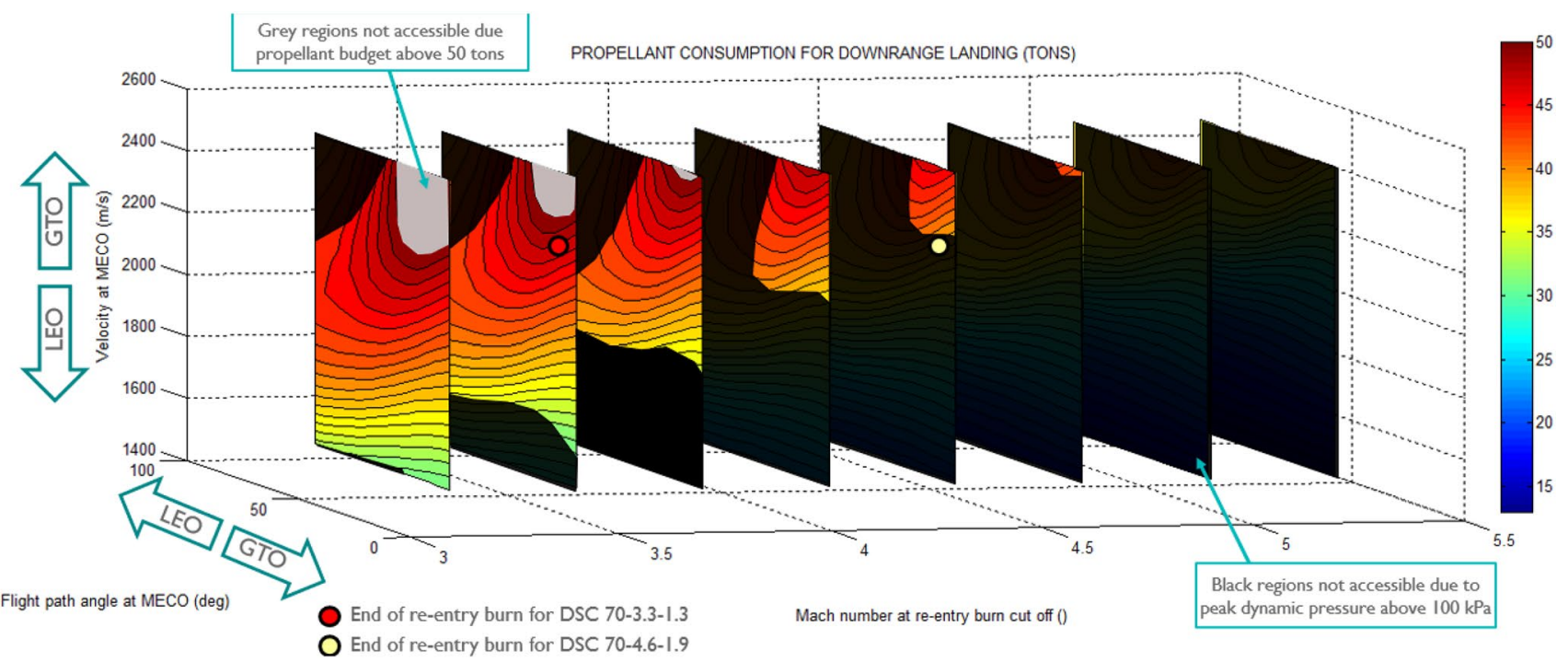

Fig. 14 End-2-end propellant budget as a function of conditions at MECO, "grid fins" configuration with AoA=185 deg during the aerodynamic phase, RETALT1 DRL

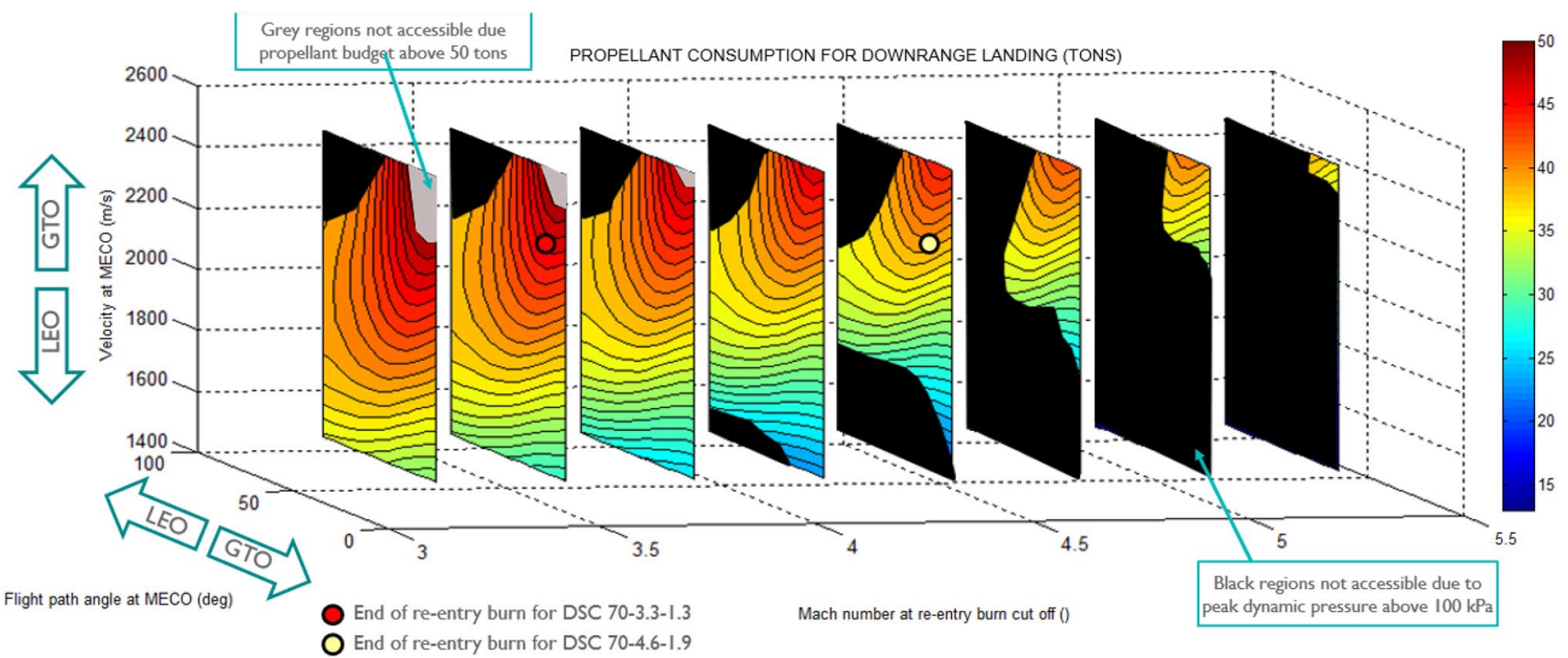

Fig. 15 End-2-end propellant budget as a function of conditions at MECO, "interstage petals " configuration with AoA=180 deg during the aerodynamic phase, RETALT1 DRL

gain in the propellant consumption is not enough to significantly change the feasible domain. The use of the interstage petals as aerobraking devices has a similar yet much stronger impact (Fig. 15). Based on the results obtained in the recovery capability analysis, the use of the interstage petals as aerobraking device during the aerodynamic phase would allow saving up to about 6.6 tons on average for the same mission (any given set of conditions at MECO), that is, about $13.2 \%$ on the total propellant budget. Again, due to the trajectory dynamics, the propellant gain is lower for very steep and high-speed conditions at MECO, therefore, the feasible domain is not expected to significantly change in that region.

In addition, a dispersion budget could be computed to define the characteristics of the trajectory control that shall allow a precise landing. Figure 16 shows the trajectory dispersions budget for each phase, for the proposed RETALT1 configurations. This dispersions budget can be used to derive preliminary requirements for the GNC. The range capability at the beginning of the landing phase corresponds to the best-case scenario in terms of propellant consumption. For the petals configuration, the range capability during landing 


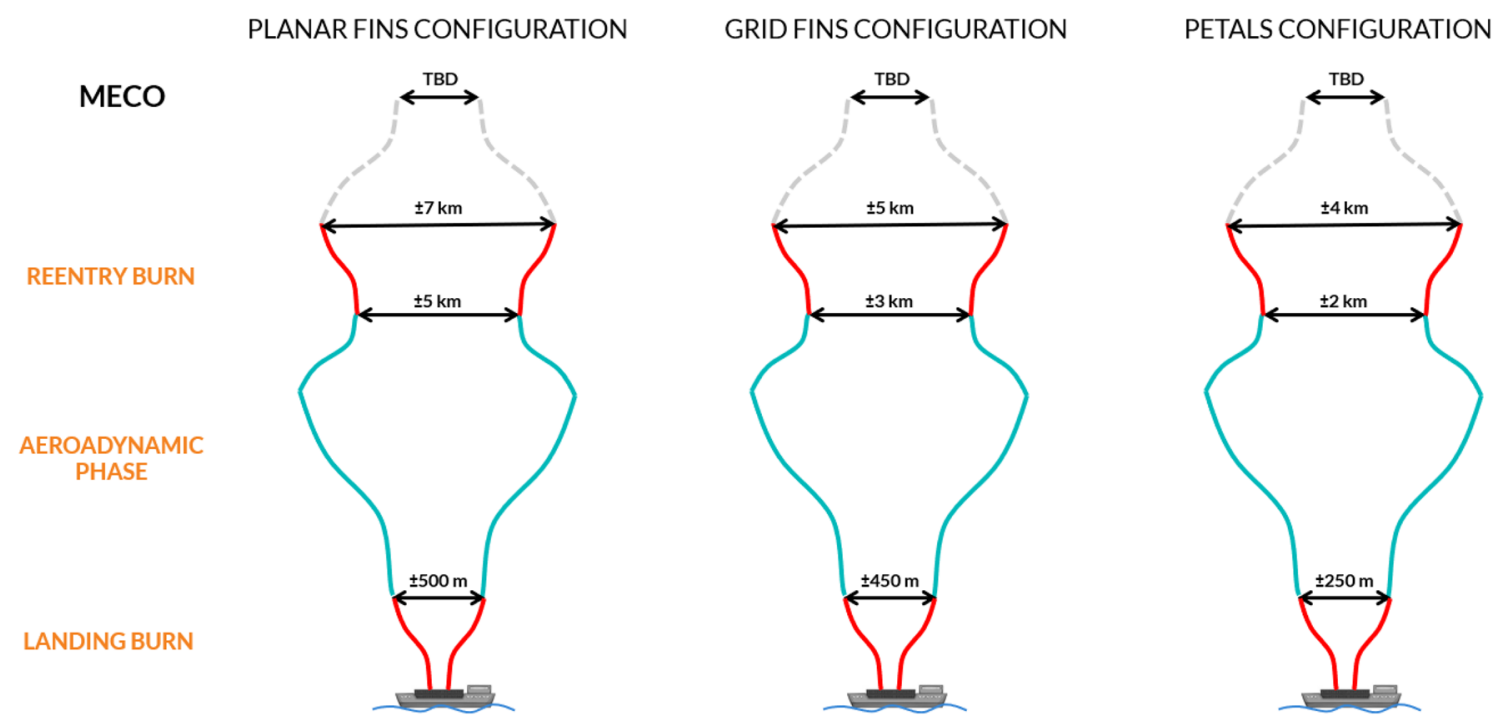

Fig. 16 Position dispersions budget of the return mission for the proposed configurations, RETALT1 DRL

could be increased anticipating the start of the landing burn, with an increased propellant consumption. If a common target of $\pm 500 \mathrm{~m}$ of position accuracy at the end of the aerodynamic phase is assumed, the start of the landing phase should occur at the same conditions for all configurations and the propellant consumption during landing will be similar.

The ACS design and sizing activities showed that the use of the interstage petals as the main ACS for the current RETALT1 configuration is considered not feasible due to current structural and mechanisms design limitations [8]. Therefore, the original baseline configuration proposed for RETALT1 cannot provide the capability to actively control the trim during the aerodynamic phase. Hence, the configuration with the planar fins as a main ACS was selected as the baseline configuration for RETALT1. The interstage configuration provides, however, very good aerobraking performance, and contributes significantly to decrease the propellant needs. Although deemed unfeasible for the RETALT1 vehicle, the impact of having the interstage petals on the overall propellant budget is significant in comparison to the planar fins. The use of such aerobraking devices is recommended for smaller launchers when actuation loads are limited and feasible solutions could be identified.

Similarly, the overall propellant budget for the RTLS scenario can be computed building an end-2-end performance map taking into account the propellant consumption required for the boostback burn plus re-entry burn and for the landing burn. The maximum propellant available of 50 tons limits the feasible domain for the RTLS mission to low speed and steep conditions at MECO. In addition, above $60 \mathrm{~km}$ downrange from the LS, RTLS is not possible for the range

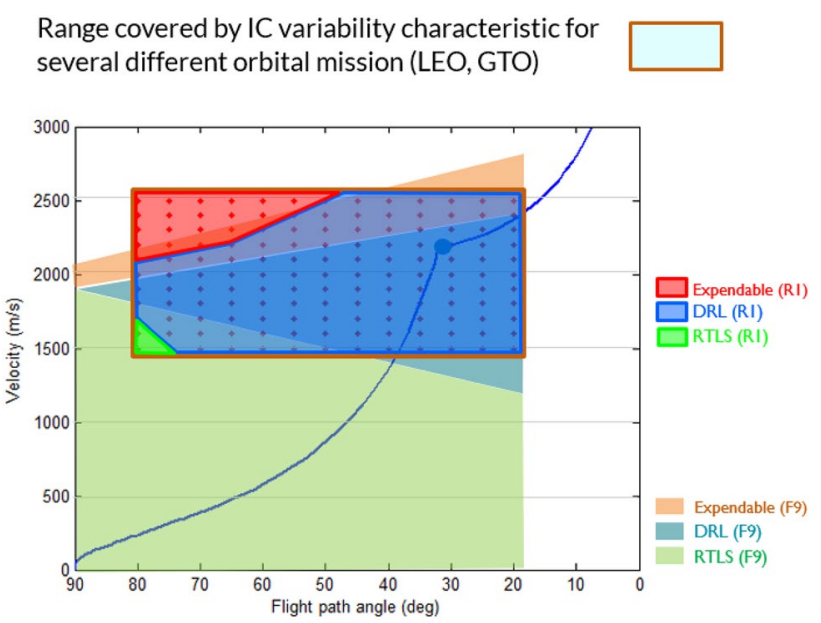

Fig. 17 Feasibility map for the recovery of RETALT1 (and comparison with reconstructed Falcon 9 performance [ ${ }^{*}$ MERGEFORMAT 7])

of conditions at MECO considered (Fig. 4). The feasible domain for the grid fins configuration is very similar to what is obtained for the planar fins, while the use of the interstage petals as aerobraking device guarantees saving about $10 \%$ of the propellant, thus increasing the feasible domain for a RTLS recovery.

In conclusion, an overall feasibility map is identified considering both the DRL and RTLS recovery strategies and as a function of the velocity and FPA conditions at MECO. Figure 17 shows the RETALT1 recovery feasibility map for the range of MECO velocity and FPA considered in this mission feasibility analysis. For the sake of comparison, the recovery map inferred for SpaceX's Falcon 9 [7] is also reported. 


\section{Entry corridor and flying qualities analysis}

Considering the need for a trim flight identified by the mission feasibility analysis, the flight characteristics and the trimmability and stability of the system-flying qualities (FQ) - are evaluated to support the definition of a trim strategy and a trim solution based on the mission needs. This is done through the identification of the AoA Entry Corridor (EC), defined as the region of the Mach-AoA plane compatible with the set of flight mechanics constraints considered, and identifies the region within which a trim solution can be identified. The AoA Entry Corridor includes uncertainties on aerodynamics, AoA, trajectory, and MCI.

The feasible domain (FD) analysis identifies the influence of the different $\mathrm{CoG}$ locations on the AoA entry corridor performance, with the objective of defining boundaries in terms of CoG position that guarantee the existence of an EC. The trim design and the FQA are carried out for all phases of the return mission of RETALT1 when the aerodynamics are non-negligible: the re-entry and landing burns and, most importantly, the aerodynamic phase. The FQA tool available in DEIMOS is used [3,9] for this analysis. This tool has been extensively used to support the mission design of the IXV [10] and Space Rider [11], among other vehicles. The IXV flight was allowed to verify the FQA tool with flight data. FQA are limited to the longitudinal plane. A neutral trim in the lateral plane is targeted for the mission design in reference conditions. In the current analysis, FQA always refers to the longitudinal plane, unless otherwise specified. Figure 18 shows the entry corridor for the planar fins configuration during the landing phase. In this case, the central engine is active and when the TVC is actuating the vehicle shall be trimmed taking into account the contribution of the thrust. The maximum TVC delection, assumed to be $5 \operatorname{deg}$ [8], is the worst-case scenario for this analysis.
Based on the models available, the planar fins are able to fully trim the vehicle during the landing phase and an entry corridor (green region in Figure 18) can be identified for the region of interest in terms of Mach-AoA.

The fins deflection required to trim the vehicle is also reported. A similar analysis has been made for the aerodynamic phase. Figure 19 shows the entry corridor for different $\mathrm{CoG}$ locations during the aerodynamic phase. If the propellant load is low, the $\mathrm{CoG}$ is forward towards the engines and an entry corridor can be identified for the region of interest in terms of Mach-AoA. In particular, the aerodynamic flight is expected to be fully trimmable and stable up to $\triangle \mathrm{AoA}$ of $10 \mathrm{deg}$, in line with the mission needs. This result is confirmed up to about 83 tons of mass, that corresponds to 34 tons of propellant loaded. At that point, instabilities bubbles start to appear in the corridor, that eventually connect when the mass is greater than 90 tons. Considering the propellant needs for the landing phase discussed in Sect. 3, these results show that the planar fins configuration assumed as a baseline for RETALT1, allows to trim the vehicle during the aerodynamic phase as required and will enable the recovery of the vehicle. Therefore, the FQA confirms the return mission to be feasible from a flight mechanics point of view, and the performance required to guarantee the recovery of the RETALT1 first stage could be met. These results have been used as input to consolidate the reference return scenario of RETALT1.

\section{Mission consolidation}

The mission design consolidation for the RETALT1 return scenarios has been carried out focusing on the baseline configuration with planar fins. Consolidated reference trajectories have been optimized considering the flight envelope and mission requirement derived from the mission feasibility analysis.
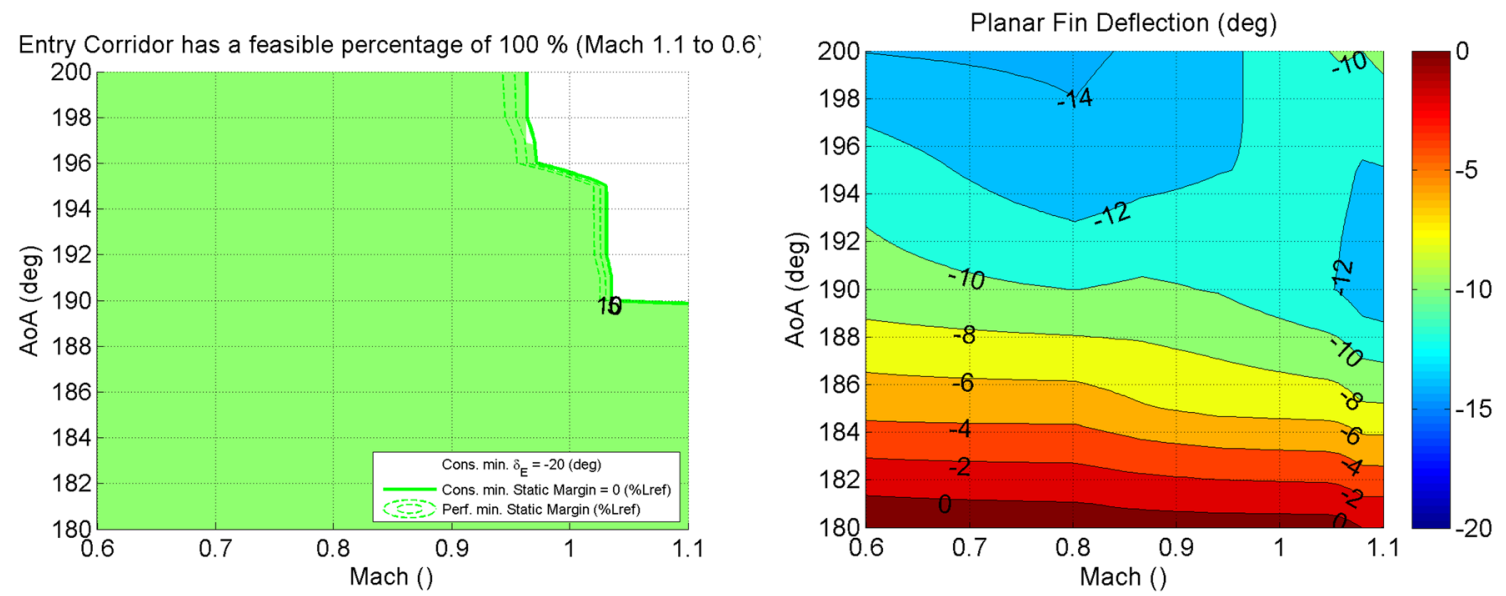

Fig. 18 AoA Entry Corridor with $\mathrm{TVC}=5 \mathrm{deg}$, planar fins configuration, landing phase 


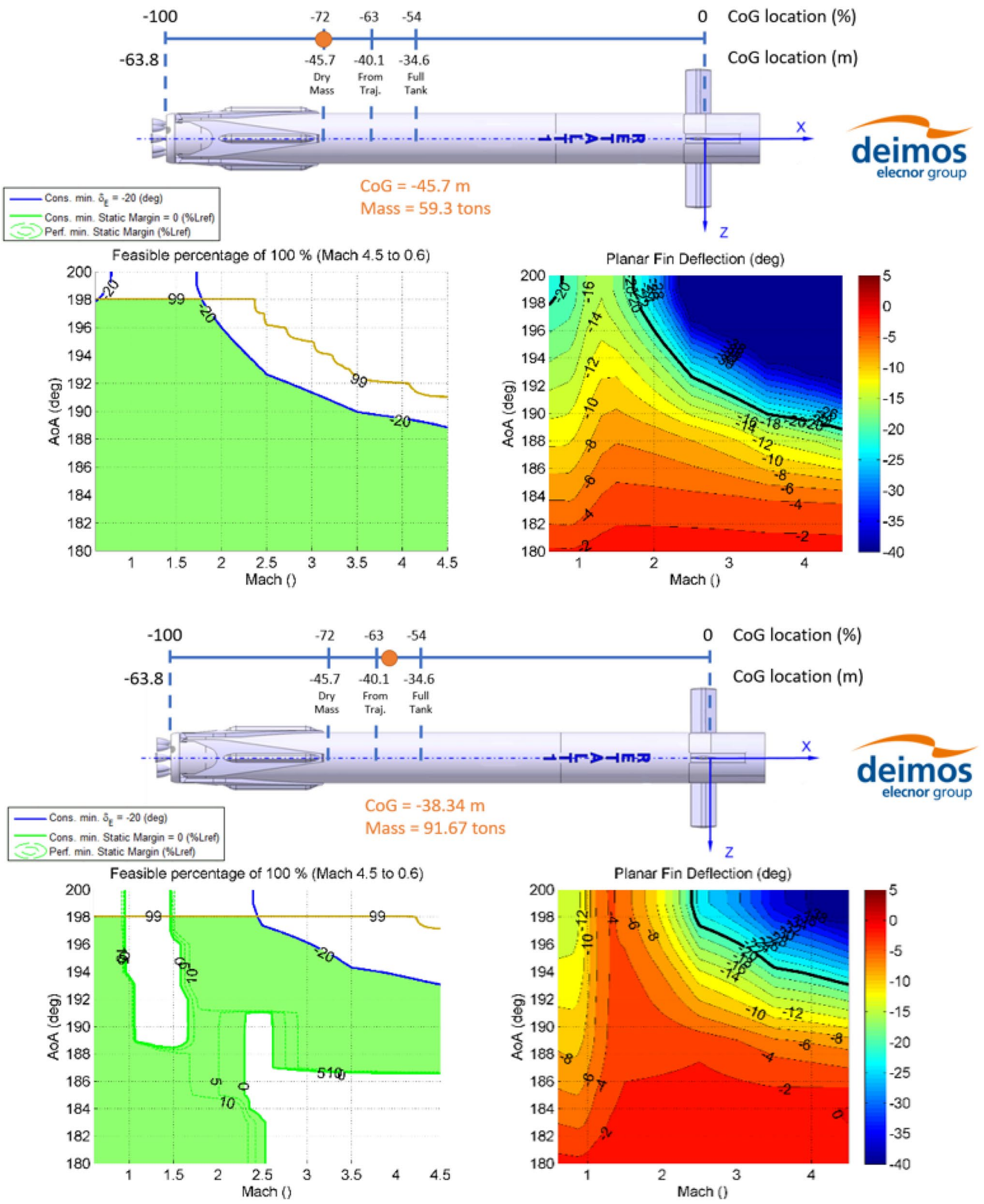

Fig. 19 Evolution of the dispersed (MonteCarlo) AoA EC, planar fins configuration, aerodynamic phase 


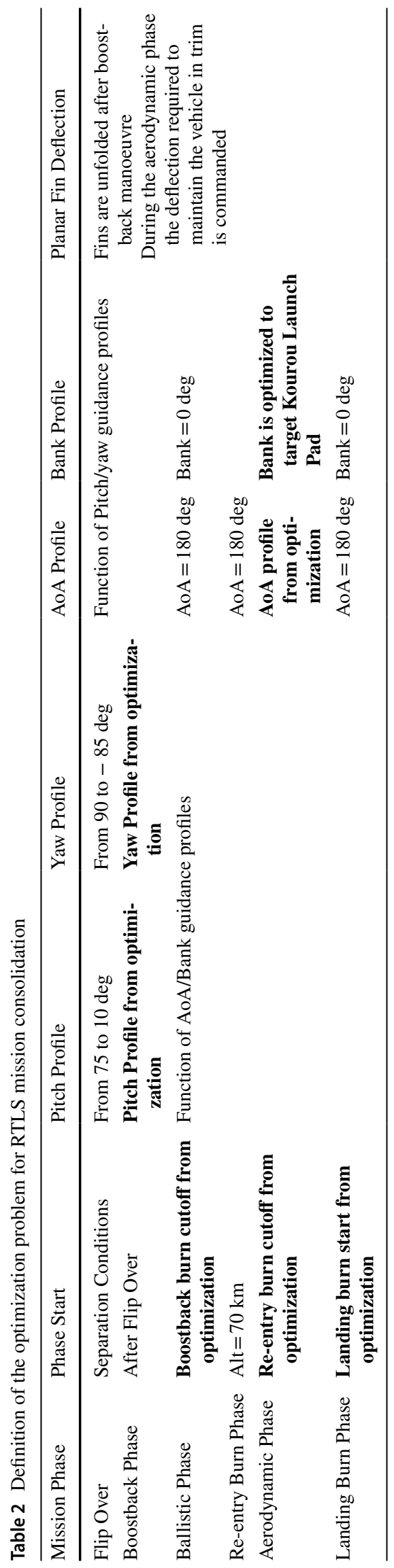

Different initial conditions for the two scenarios have been assumed in line with the feasibility domain reported in Fig. 17. Trajectory optimization is performed with the optimisation toolbox included in DEIMOS' proprietary Planetary Entry Toolbox (PETbox) [3]. The objective is to define the reference mission minimizing the mass consumption during re-entry and landing burn that is compatible with the performance needs and the mission requirements. Table 2 summarizes the definition of the optimization problem for the RTLS scenario. For the DRL scenario the same variables are used, without considering those related to the boostback burn. The consolidated trajectories respect all the mission constraints, with margins to compensate for uncertainties and dispersions. The angle of attack during the aerodynamic phase is optimized (Fig. 20) to have a different value to 180 degrees and, therefore, obtaining two main benefits: increased drag acceleration which contributes to the braking allowing propellant saving, and creation of positive lift acceleration that can be used to control the trajectory and generate enough crossrange capability to steer the vehicle toward the landing site (Fig. 21). The propellant consumption for the DRL scenario is 45.3 tons, while for the RTLS scenario it is 48.7 tons as a result of the additional boostback maneuver, and in line with the preliminary needs estimated in Sect. 3. However, the boostback maneuver partially contributes to slow down the 1st stage reducing the propellant budget for the re-entry burn in the case of RTLS by about $30 \%$ with respect to the DRL scenario (Fig. 21). The trim AoA solution for the aerodynamic phase is within the corridor avoiding instability regions.

\section{Conclusions and way forward}

The mission engineering activities of RETALT carried out so far demonstrated that the recovery of the first stage of RETALT1 is feasible for a recovery strategy based on the use of retro-propulsion and having 50 tons of overall propellant budget allocated for the return phase. The propellant budget assigned for the return mission enables the recovery of the RETALT1 booster for a wide range of launch missions, that can be performed either with a Downrange Landing on a barge or with a Return To Launch Site depending on the conditions at MECO. Needs for the vehicle recovery were identified and allowed the definition of preliminary mission requirements that drove the consolidation of the return mission design. In addition, the assessment of the capabilities of the proposed configurations to perform a return mission enabled the identification of preliminary flight and landing loads to support the sizing of the aerodynamic actuators, and the design of the GNC solution.

In the second part of the project activities, the consolidated mission baseline will be used to carry out a detailed flight performance assessment and the verification of the return mission design, to support the evaluation of the applicability 

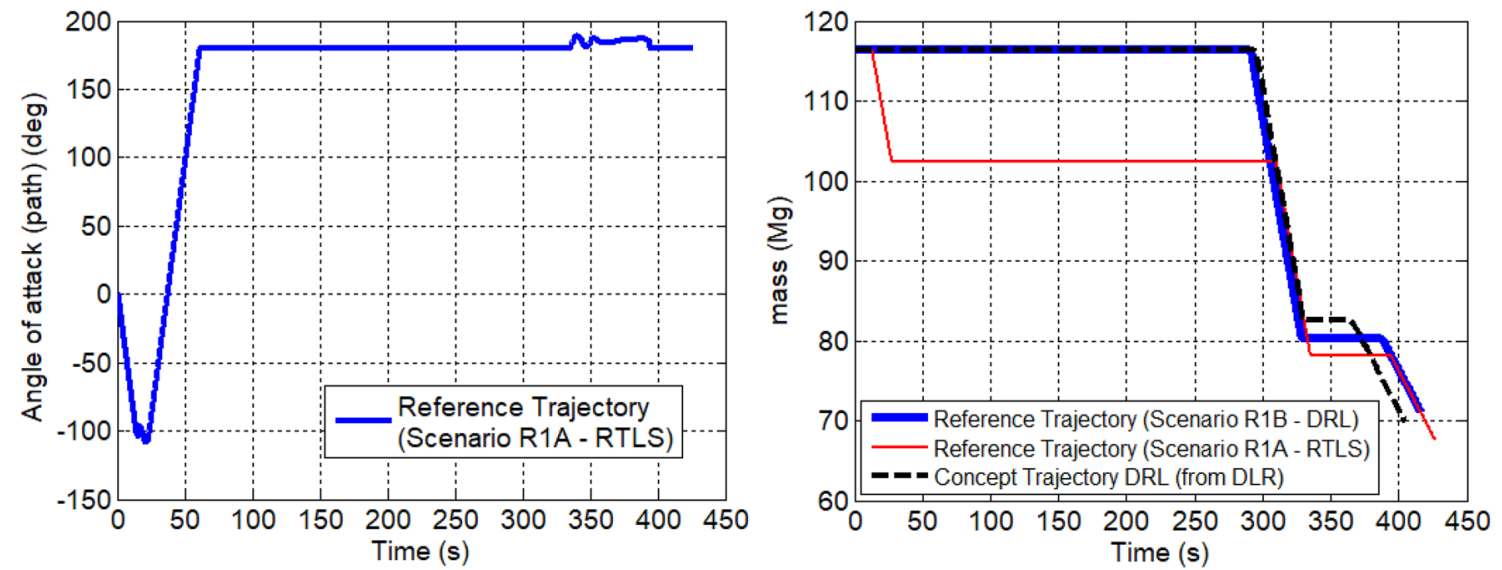

Fig. 20 Optimised AoA profile (left) and total mass profile for the RTLS (R1 A) and DRL(R1-B) scenarios

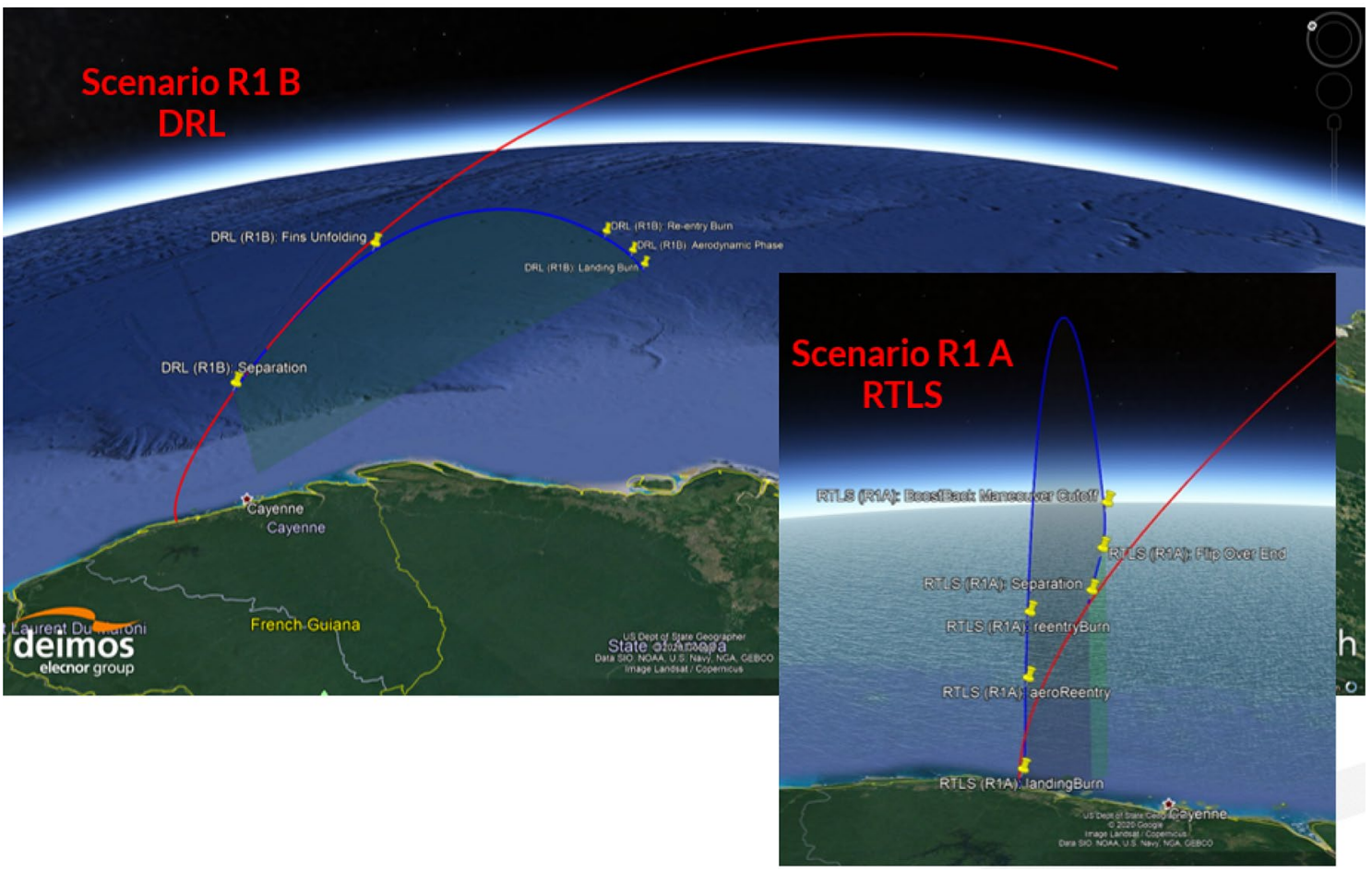

Fig. 21 Google Earth representation of the consolidated return trajectories: RTLS (R1 A) and DRL(R1-B) scenarios

of the technology solutions developed for the recovery of the RETALT1 booster.

Acknowledgements The RETALT project has received funding from the European Union's Horizon 2020 research and innovation framework program under grant agreement No 821890.

Open Access This article is licensed under a Creative Commons Attribution 4.0 International License, which permits use, sharing, adaptation, distribution and reproduction in any medium or format, as long as you give appropriate credit to the original author(s) and the source, provide a link to the Creative Commons licence, and indicate if changes were made. The images or other third party material in this article are included in the article's Creative Commons licence, unless indicated otherwise in a credit line to the material. If material is not included in the article's Creative Commons licence and your intended use is not permitted by statutory regulation or exceeds the permitted use, you will need to obtain permission directly from the copyright holder. To view a copy of this licence, visit http://creativecommons.org/licenses/by/4.0/. 


\section{References}

1. Patureau de Mirand, A., Bahu, J.M., Louaas, E.: Ariane Next, a vision for a reusable cost-efficient European rocket. In: 8th European Conference for Aeronautics and Space Sciences (EUCASS), Madrid, Spain (2019), https://doi.org/10.13009/ EUCASS2019-949

2. Marwege, A., Klevanski, J., Riehmer, J., Kirchheck, D., Karl, S., Bonetti, D., Vos, J., Jevons, M., Krammer, A., Carvalho, J.: Retro propulsion assisted landing technologies (RETALT): current status and outlook of the EU Funded Project on Reusable Launch Vehicles. In: 70th International Astronautical Congress (IAC), Washington D.C., United States (2019).

3. Bonetti, D., Parigini, C., De Zaiacomo, G., Pontijas Fuentes, I., Blanco Arnao, G., Riley, D., Sanchéz, M.: Petbox: Flight qualified tools for atmospheric flight. In: 6th International Conference on Astrodynamics Tools and Techniques (ICATT), Darmstadt, Germany (2016).

4. Bonetti, D., De Zaiacomo, G., Blanco Arnao, G., Medici, G., Van Hove, B., Bunt, R.: DEIMOS' R\&D on reusable launchers' technologies. In: Congreso de Ingenieria Espacial, Madrid, Spain (2020).

5. Marwege, A., et al.: Wind tunnel experiments of retro-propulsion assisted landing vehicles in the aerodynamic descent phase (RETALT). In: Submitted to the CEAS Space Journal, (2020)

6. Charbonnier, D., et al.: Computational Fluid Dynamics investigations of Aerodynamic Control surfaces of a vertical landing configurations. In: Submitted to the CEAS Space Journal, (2020)
7. Reddit.com.: Falcon 9 stage 1 landing analysis. https://www.reddit.com/r/spacex/comments/7ajf09/falcon_9_stage_1_landing_ analysis/. Accessed 2 June 2020.

8. Krammer, A., et al.: Fin actuation, thrust vector control and landing leg mechanisms design for the RETALT VTVL launcher. In: Submitted to the CEAS Space Journal, (2020)

9. Haya Ramos, R., Peñin, L. F., Parigini, C., Kerr, M., Preaud, J.P., Ganet, M., Bennani, S., Martinez Barrio, A.: Flying Qualities Analysis for Re-entry Vehicles: Methodology and Application. AIAA Guidance, Navigation, and Control Conference (AIAA-GNC), Portland, USA (2011), https://doi.org/10.2514/6. 2011-6344

10. Bonetti, D., De Zaiacomo, G., Blanco Arnao, G., Pontijas Fuentes, I., Parigini, C., Haya Ramos, R., Freixa, J.: IXV mission analysis and flight mechanics: from design to postflight. In: 23rd Conference of the Italian Association of Aeronautics and Astronautics (AIDAA), Torino, Italy (2015).

11. Bonetti, D., De Zaiacomo, G., Blanco Arnao, G., Medici, G. Pontijas Fuentes, I., Parreira, B.: Space rider mission engineering. In: 8th European Conference for Aeronautics and Space Sciences (EUCASS), Madrid, Spain (2019), https://doi.org/10.13009/ EUCASS2019-633

Publisher's Note Springer Nature remains neutral with regard to jurisdictional claims in published maps and institutional affiliations. 